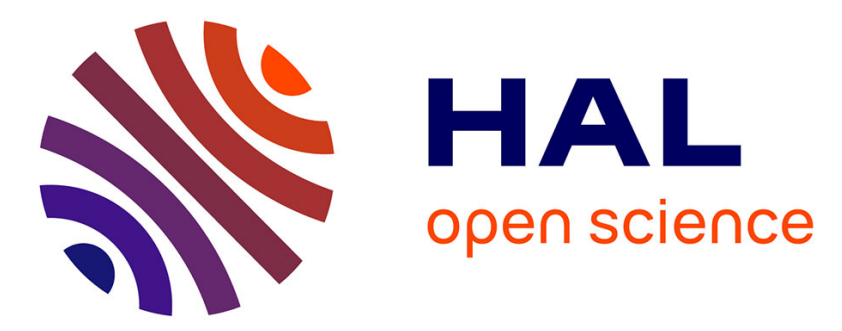

\title{
Intercomparison of Flow and Transport Models Applied to Vertical Drainage in Cropped Lysimeters
}

Michael Herbst, Wieslaw Fialkiewicz, Tao Chen, T. Pütz, Dominique Thiéry, Christophe Mouvet, Georges Vachaud, Harry Vereecken

\section{- To cite this version:}

Michael Herbst, Wieslaw Fialkiewicz, Tao Chen, T. Pütz, Dominique Thiéry, et al.. Intercomparison of Flow and Transport Models Applied to Vertical Drainage in Cropped Lysimeters. Vadose Zone Journal, 2005, 4 (2), pp. 240-254. 10.2136/vzj2004.0070 . hal-01061898

\section{HAL Id: hal-01061898 https://hal-brgm.archives-ouvertes.fr/hal-01061898}

Submitted on 8 Sep 2014

HAL is a multi-disciplinary open access archive for the deposit and dissemination of scientific research documents, whether they are published or not. The documents may come from teaching and research institutions in France or abroad, or from public or private research centers.
L'archive ouverte pluridisciplinaire HAL, est destinée au dépôt et à la diffusion de documents scientifiques de niveau recherche, publiés ou non, émanant des établissements d'enseignement et de recherche français ou étrangers, des laboratoires publics ou privés. 


\section{Unsaturated methabenzthiazuron transport in a cropped lysimeter: comparison between models and measurements}

M. Herbst*, W. Fialkiewicz, T. Chen, T. Pütz, D. Thiery, C. Mouvet, G. Vachaud and H. Vereecken

Michael Herbst, m.herbst@fz-- elich.de Thomas Pütz, t.puet inelic te

Harry Vereeck, 1.vereec @ @ uelich.de ICG IV Institu ff Agrosphe FZJ Research Ce a Jülich D- 52425 Jülich Germany

Wieslav Fialkiewicz,w.fialkiewicz@brgm.fr Domique Thiery,d.thiery@brgm.fr Christophe Mouvet, c.mouvet@brgm.fr Bureau de Recherches Geologiques et Minieres BRGM

Avenue Claude Guillemin F 45060 Orleans Cedex 02 France

Tao Chen, chen@hmg.inpg.fr

Georges Vachaud, georges.vachaud@ hmg.inpg.fr Laboratoire d'etude des Transferts en Hydrologie et Environnement LTHE (UMR CNRS 5546, UJF, INPG, IRD)

BP53

38041 Grenoble cx09

France 


\section{$1 \quad$ ABSTRACT}

2 The vertical water flow, heat flow and transport of the herbicide methabenzthiazuron were

3 monitored for 627 days in lysimeters sampled at a field site close to the research centre Jülich,

4 Germany. During this period the lysimeters were cropped with winter wheat, winter barley

5 and oat. The models TRACE, MARTHE, ANSWERS and MACRO were applied to the

6 lysimeter data with the scope of upscaling local scale process understanding for regional

7 scale. MARTHE and TRACE solve the 3-d Richards' equation for variably saturated water 8 flow. MACRO is a 1-d model based on the Richards' Equation and accounting for

9 preferential flow in the unsaturated zone, while ANSWERS is a regional scale capacity based watershed model. Measurements of soil moisture, evapotranspiration, drainage, soil temperature, pesticide residues and leaching are used for comparison with model results. Although the adopted models differ in terms of model concepts, the use of model performance indices proved a proper simulation of water flow for all models. The heat flow is also well described with ANSWERS, MARTHE and MACRO. Larger deviations were found between model results and measured pesticide transport. An inadequate reproduction of the measured MBT degradation was found for the available model input parameters. A very small amount of MBT leaching, observed in the measurements, was only reproduced with MACRO after strong calibration. In other respects only plant parameters were calibrated. Calibration of the crop conversion factor used for scaling of the potential evapotranspiration was found to be a crucial parameter for the adequate description of the water balance by the models.

\section{INTRODUCTION}

During the last decades a significant increase of water bodies contaminated with pesticides has been observed for various areas worldwide. Due to the use of aquifers for drinking water supply, an assessment and a sound prediction of the impact of agricultural practice concerning 
1 pesticide application is mandatory. In the framework of the EU-Project PEGASE (Pesticides

2 in European Groundwaters: detailed study of representative aquifers and simulation of 3 possible evolution scenarios) the test area 'Zwischenscholle' $\left(20 \mathrm{~km}^{2}\right)$, located $30 \mathrm{~km}$ west of

4 Cologne (Germany), was selected for a joint modelling on pesticide transport at regional scale 5 with four different modeling approaches. Two of these four models are MARTHE and 6 TRACE, which calculate water flow in variable saturated porous media using a generalized 7 Richards' equation. The other two models, MACRO and ANSWERS are used in a coupled approach, linking both aforementioned unsaturated zone models with a groundwater flow model. The validation of water flow and transport processes at regional scale is rather difficult. Thus in a first step a lysimeter data set was chosen to check the modelling of water flow and pesticide transport at local scale. Cropped lysimeters were used to monitor water

12 flow and fate of the pesticide methabenzthiazuron (MBT) for a period of almost two years. The lysimeter station was located in the test area 'Zwischenscholle' and the lysimeter soil approximates some of the soils found in the test area. The experimental data of the lysimeter were supposed to validate the modelling of plant related processes, water flow and pesticide transport in the unsaturated zone at local scale.

17 Large undisturbed lysimeters are a common experimental setup for investigations of pesticide transport (Bergström, 1990; Boesten, 1994; Keller at al., 1995; Vink et al., 1997; Schoen et al., 1999; Mikata et al., 2003), they are particularly applied for pesticide registration purposes. The main advantages of lysimeters are the controlled boundary conditions and the 21 measurement of actual evapotranspiration, soil moisture and drainage for a large soil volume. 22 In addition the pesticide concentrations of the drainage water can be determined. The representativeness of lysimeter observations for the field scale behaviour of transport processes is still debated. Compared with field measurements with suction plates Jene et al. (1997) measured $40 \%$ more bromide leaching in lysimeters. Comparative modeling of 
1 pesticide transport has been the subject of several studies. Model comparisons on pesticide

2 transport have been carried out for lysimeters (Bergtröm and Jarvis, 1994; Vink et al., 1997;

3 Francaviglia et al., 2000) as well as for field studies (Pennel et al., 1993; Diekkrüger et al.

4 1995a; Armstrong et al., 2000; Gottesbüren et al. 2000; Tiktak, 2000; Vanclooster and 5 Boesten, 2000). The most recent and probably most extensive model comparsion was 6 summarized by Vanclooster et al. (2000). The major outcome of this comparative pesticide 7 modelling on lysimeter and field data by Armstrong et al. (2000), Francaviglia et al. (2000), 8 Gottesbüren et al. (2000), Tiktak (2000) and Vancloster and Boesten (2000) is what 9 Diekkrüger et al. (1995a) also stressed: The influence of the modellers' experience on model results is large, probably larger than the influence of the selected model concept. Bergström and Jarvis (1994) found very similar results for the five models included in their comparison.

12 They also note that, besides from taking the relevant processes into account, the identification of correct model input parameters plays a key role in predicting pesticide transport.

Methabenzthiazuron is an effective herbicide in grain and certain vegetable crops. It is classified as a rather persistent compound (Rouchaud et al. 1988) with a high sorptivity (Diekkrüger et al., 1995b; Wüstemeyer, 2000).

MARTHE and TRACE are rather recent developments, based on the extension of codes originally developed for the description of groundwater transport at regional scales. TRACE comes from 3DFEMWATER (Yeh at al., 1992), which allowed to calculate both saturated and unsaturated water flow. MACRO is a classical 1-dimensional model. Since the 21 introduction of MACRO it has already been used in several model comparison studies on 22 pesticide fate modelling (Bergström and Jarvis 1994; Diekkrüger et al. 1995a; Vink et al. 1997; Vanclooster et al., 2000), where it has proven a broad applicability to several pesticide transport problems. During this study the version 5.0 is applied. ANSWERS is a capacity based regional scale model for the vadose zone transport of solutes. It has already been 
1 evaluated in the context of agricultural non-point source water quality models (Kosky and

2 Engel, 1997). The model concepts are rather contrasting (Table 1). MACRO is the only model

3 accounting for preferential flow and transport. Except for ANSWERS all models are based on

4 the Richards' equation for the calculation of soil water flow. MACRO and ANSWERS solve

5 the convection-dispersion equation (CDE) with a common numeric scheme, whereas TRACE

6 is coupled with 3dLEWASTE, which applies a hybrid Lagrangian/Eulerian method to solve

7 the CDE and MARTHE uses the total variation diminishing method. For pesticide

8 degradation only TRACE coupled with 3dLEWASTE uses a simple first-order kinetics

9 approach, whereas all the other models allow the use of a soil temperature and moisture

10 dependent biodegradation approach.

11 Basically, there are three main objectives: (i) to identify the crucial plant parameters and test 12 the applicability of the relevant plant data base, (ii) to check the model performances on water flow and MBT transport and (iii) to compare the performance of the different model concepts.

\section{METHODS AND DATA}

16

17

\section{Experimental data}

Five undisturbed soil monoliths (free draining lysimeters) containing an Orthic Luvisol were used to monitor the soil water balance. The sampling distance between the monoliths was roughly $1 \mathrm{~m}$. The monoliths were $1.1 \mathrm{~m}$ long and had a surface area of $1.0 \mathrm{~m}^{2}$. Three pedogenetic soil horizons were distinguished (Table 2). One of the lysimeters was treated with a dose of $2.8 \mathrm{~kg} \mathrm{ha}^{-1}$ as TRIBUNIL ${ }^{\circledR}$ corresponding with an active ingredient application of $248.11 \mathrm{mg} \mathrm{m}^{-2}$ [phenyl-U- ${ }^{14} \mathrm{C}$ ]methabenzthiazuron during the pre-emergence period of winter wheat at the $25^{\text {th }}$ of November 1988. The winter wheat (Triticum Aestivum L.) was harvested and soil samples were taken with a hand auger at $3^{\text {rd }}$ of August 1989 (252 days after

\footnotetext{
${ }^{\circledR}$ Reg. Trademark, Bayer AG
} 
1 application). In the following vegetation period winter barley (Hordeum Vulgare L.) was

2 cropped and harvested on the $11^{\text {th }}$ of May 1990. The next vegetation was oat, which was 3 harvested at the $13^{\text {th }}$ of August 1990, when a last soil sampling was carried out 627 days after

4 the application.

5 From the $25^{\text {th }}$ of November 1988 until the $13^{\text {th }}$ of August 1990 the meteorological parameters 6 precipitation, air humidity, air temperature, wind speed and radiation were monitored on a 7 daily basis (Figure 1). Roughly every three days soil moisture was measured with a neutron 8 probe. Leachate was collected on a three weekly basis. The amount of lysimeter drainage can 9 be measured directly while the actual evapotranspiration $\mathrm{Et}_{\mathrm{a}}(\mathrm{mm})$ was calculated from the 10 soil water balance,

$11 E t_{a}=P-D-\Delta \theta$

12 where $\mathrm{P}$ is the precipitation $(\mathrm{mm}), \mathrm{D}$ is the drainage $(\mathrm{mm})$ and $\Delta \theta$ is the change of soil 13 moisture (mm) during the considered period of time.

14 MBT was extracted from the soil with acetone/ethyl acetate/chloroform. Using thin-layer 15 chromatography the detection limit of ${ }^{14} \mathrm{C}$-labeled MBT was $0.67 \mu \mathrm{g}{ }^{-1}$.

\section{TRACE/3dLEWASTE}

TRACE (Vereecken et al., 1994) calculates the 3-dimensional unsaturated/saturated water flow in porous media. A modified Picard-iteration scheme (Celia et al., 1990) is applied in combination with a preconditioned conjugate gradient method in order to solve the following

21 generalized 3-dimensional Richards`equation numerically,

$22 \quad F_{h} \frac{\partial h(\vec{s}, t)}{\partial t}=\nabla(K(\vec{s}, h) \nabla H(\vec{s}, h))+Q(\vec{s}, t) \quad$ with $\quad F_{h}=\frac{\partial \theta}{\partial h}+S_{h}$

23 where $\mathrm{K}$ is the hydraulic conductivity $\left(\mathrm{LT}^{-1}\right), \vec{s}$ is the position vector in a three dimensional 24 space, $h$ is the pressure head $(\mathrm{L}), \mathrm{H}$ is the total head $(\mathrm{L}), \mathrm{Q}$ is the source/sink term $\left(\mathrm{T}^{-1}\right), \theta$ is 
1 the soil water content $\left(\mathrm{L}^{3} \mathrm{~L}^{-3}\right), \mathrm{t}$ is time $(\mathrm{T}), \mathrm{S}_{\mathrm{h}}$ is the specific storage coefficient $\left(\mathrm{L}^{-1}\right)$ and $\mathrm{F}_{\mathrm{h}}$ is

2 the specific water capacity $\left(\mathrm{L}^{-1}\right)$. For the spatial discretization hexahedral Galerkin-type finite

3 elements are used. In order to take plant related processes into account the crop growth

4 module SUCROS (Simplified and Universal Crop growth Simulation, Spitters et al., 1988) is

5 implemented. In contrast to many other plant modules SUCROS estimates the assimilation

6 rate from plant specific photosynthesis parameters and radiation. The calculated increase in

7 biomass is used to predict leaf area growth and leaf area index (LAI), which is therefore not

8 model input. The required plant data values can e.g. be found in van Heemst (1988). The crop

9 coefficients ( $\mathrm{K}_{\mathrm{c}}$-values) for the scaling of the reference evapotranspiration can be assigned for

10 different seasonal stages according to the approach of Doorenbos and Pruitt (1978). Based on

11 LAI the potential evapotranspiration is split into the fractions of potential evaporation and

12 potential transpiration according to Beer's law. The actual transpiration is calculated from the

13 potential transpiration in dependence of the pressure head according to the approach of

14 Feddes et al. (1978). For the soil evaporation a flux boundary is applied to the uppermost

15 element until the given pressure head $h_{\min }$ is reached (e.g. $\left.-10^{-4} \mathrm{~cm}\right)$. At this point TRACE

16 switches to a fixed head boundary condition set to $\mathrm{h}_{\min }$.

17 3dLEWASTE (Yeh et al., 1992) is a hybrid Lagrangian-Eulerian finite element model of reactive solute transport through unsaturated/saturated media. 3dLEWASTE numerically

19 solves the Lagrangian form of the convection-dispersion transport equation (CDE),

$20 \quad \frac{D C}{D t}+(\nabla \cdot \vec{V}) C=\nabla \cdot \vec{D} \cdot \nabla C$

21 where $\mathrm{C}$ is the solute concentration $\left(\mathrm{M} \mathrm{L}^{-3}\right), \mathrm{DC} / \mathrm{Dt}$ is the material derivative of $\mathrm{C}$ with respect

22 to time t, $\vec{D}$ is the dispersion coefficient tensor $\left(\mathrm{L}^{2} \mathrm{~T}^{-1}\right)$ and $\vec{V}$ is the pore velocity vector

$23\left(\mathrm{~L} \mathrm{~T}^{-1}\right)$ for the $\mathrm{x}, \mathrm{y}$ and $\mathrm{z}$ direction. Here the advective term is solved in a mobile (Lagrangian)

24 coordinate system using a single step reverse particle tracking, while the diffuse term is 
1 solved in a fixed (Eulerian) coordinate system. A backward differencing scheme in time is

2 applied. A more detailed description of the hybrid Lagrangian-Eulerian approach can be

3 found at Yeh et al. 1992. For microbial decay a first order degradation rate coefficient is

4 applied to the sorbed and the liquid concentrations. A linear, Freundlich or Langmuir

5 isotherm can be applied for sorption. For the coupling between TRACE and 3dLEWASTE a

6 file is used containing the Darcy fluxes and the water contents for every finite element at 7 every time step. For simplicity the coupled model TRACE and 3dLEWASTE is referred to as 8 'TRACE' during the following text.

\section{ANSWERS}

The Areal Non-point Source Watershed Environmental Response Simulation, ANSWERS

12 (Bouraoui et al., 1997), is originally a watershed scale, diffuse pollution model for long term simulation. The core of the system is a one-dimensional vertical model based on a capacity approach for the soil water flux. A variable vertical segmentation is considered to account for water movement through the soil profile. Infiltration into the uppermost layer is simulated by the Green and Ampt equation (Green and Ampt, 1911). Soil water redistribution from upper layer of soil to the root zone (discretized in 9 layers) is determined with the use of a Brooks and Corey type equation (Brooks and Corey, 1964) on the basis of vertical downwards gravity flow, with a hydraulic conductivity related to the average water content of the upper layer. Similarly, percolation from root zone to the underlying unsaturated zone (drainage) is determined with a hydraulic conductivity related to the average water content of the root zone. The main parameters describing the hydraulic properties of the soil are the saturated hydraulic conductivity $\mathrm{K}_{\mathrm{s}}\left(\mathrm{cm} \mathrm{h}^{-1}\right)$, the porosity $\Phi\left(\mathrm{cm}^{3} \mathrm{~cm}^{-3}\right)$, the residual water content $\theta_{\mathrm{r}}\left(\mathrm{cm}^{3} \mathrm{~cm}^{-3}\right)$, the pore size distribution index $\lambda_{b}(-)$, the bubbling pressure $\psi_{b}(\mathrm{~cm})$ and the field capacity $F_{c}$ 
1 (cm). They are obtained from soil texture and organic matter content with the Pedotransfer

2 functions of Rawls and Brakensiek (1989).

3 Soil evaporation and plant transpiration are modelled separately using Ritchie's equation

4 (Ritchie, 1972), where soil evaporation is related to the soil moisture of the upper layer and

5 the leaf area index LAI $\left(\mathrm{m}^{2} \mathrm{~m}^{-2}\right)$. Plant transpiration is extracted from root zone assuming a

6 uniform root profile. The parameters describing the plant behaviour in terms of water uptake

7 and actual evapotranspiration are obtained from a database including 78 different types of crop (Knisel, 1993). From sowing to harvest values of the LAI and root depth are given for

9 phenological stages.

The transport of solutes is calculated with the convection-dispersion equation. For sorption, degradation and plant root uptake of pesticides the approach of ANSWERS is similar to GLEAMS (Knisel, 1993). Two important assumptions are made: the degradation is only a function of temperature (zero below $0^{\circ} \mathrm{C}$ and maximum at $25^{\circ} \mathrm{C}$ ) and plant uptake is $10 \%$ of water uptake. For the degradation of pesticides alternatively the equation of Graham-Bryce et al. (1982) accounting for soil temperature and soil moisture dependent decay (Eq. 9) can be used.

\section{MACRO}

MACRO 5.0 (Jarvis et al. 2004) is a one-dimensional dual-permeability model, operating at the scale of a soil profile. The model accounts for preferential flow and transport in soil macropores by dividing the soil pore system into two parts, one part with a high flow and low storage capacity (macropores) and the remainder with a low flow and a high storage capacity (micropores). The boundary between the pore regions is defined by the fixed pressure head $\mathrm{C}_{\text {ten }}$ 
$1 \quad \mathrm{~K}_{\mathrm{mi}}\left(\mathrm{L} \mathrm{T}^{-1}\right)$. The 1-dimensional form of the Richards equation is used to model flow in the

2 micropores,

$3 \quad F_{h} \frac{\partial h}{\partial h}=\frac{\partial}{\partial z}\left(K(z, h)\left(\frac{\partial h}{\partial z}+1\right)\right)-Q(z, t) \quad$ with $\quad F_{h}=\frac{\partial \theta}{\partial h}$

4 where $\mathrm{z}$ is the vertical coordinate (L). Eq. 4 is solved for finite differences using the implicit

5 iterative procedure proposed by Celia et al. (1990). Soil water retention and unsaturated hydraulic conductivity are calculated using a modified form of the Mualem/van Genuchten approach (van Genuchten, 1980; Vogel et al., 2001) accounting for the macropore/micropore dichotomy by using the boundary pressure head partitioning the total porosity into micropores and macropores (Wilson et al., 1992; Mohanty et al., 1997). Flow in the macropores is calculated using the kinematic wave equation (Germann, 1985), assuming gravity-dominated flow (i.e. neglecting capillarity). The hydraulic conductivity function in the macropores is given as a simple power law expression of the macropore degree of saturation.

The one-dimensional convection-dispersion equation is applied for solute transport in the

14 micropores,

$$
\frac{\partial\left(C \theta_{m}+\left(1-f_{\text {mac }}-f_{n e}\right) \rho_{b} S\right)}{\partial t}=\frac{\partial}{\partial z}\left(D \theta_{m} \frac{\partial C}{\partial z}-q C\right)-\sum U_{i}
$$

where the source/sink term $\mathrm{U}_{\mathrm{i}}\left(\mathrm{M} \mathrm{L}^{-3} \mathrm{~T}^{-1}\right)$ represents different processes like mass exchange between flow domains, kinetic sorption, solute uptake by the crop, biodegradation and lateral leaching losses to drains or groundwater. $\mathrm{S}$ is the sorbed concentration $\left(\mathrm{M} \mathrm{L}^{-3}\right), \mathrm{f}_{\operatorname{mac}}$ is the mass fraction of solid material in contact with water in the macropores $(-), f_{n e}$ is the fraction of the 21 solid material providing non-equilibrium sorption $(-), \rho_{\mathrm{b}}$ is the soil bulk density $\left(\mathrm{M} \mathrm{L}^{-3}\right), \theta_{\mathrm{m}}$ is the mobile water content $\left(\mathrm{L}^{3} \mathrm{~L}^{-3}\right), \mathrm{q}$ is the water flow $\left(\mathrm{L} \mathrm{T}^{-1}\right)$ and $\mathrm{D}$ is the Dispersion coefficient $\left(\mathrm{L}^{2}\right.$ $\mathrm{T}^{-1}$ ). Transport in macropores is calculated neglecting dispersion-diffusion, but accounting for 24 adsorption by the parameter $\mathrm{f}_{\mathrm{mac}}(-)$ that partitions the sorption constant between the two flow 
1 regions. Diffusive mass exchange between the two pore regions is calculated using approximate

2 first-order equations based on an effective diffusion path length $\mathrm{a}_{\text {scale }}(\mathrm{L})$. Solute transport is

3 solved by a Crank-Nicolson finite difference scheme utilizing an iterative, fully upstream

4 weighting procedure with an empirical correction for numerical dispersion.

5 Root water uptake is calculated from evaporative demand, root distribution and soil moisture

6 using a modified version of the approach developed by Feddes et al. (1978) accounting for

7 water stress compensation (Jarvis, 1989). It is assumed, the crop can adjust to stress in one

8 part of the root system by increasing uptake from other parts where the soil moisture

9 conditions are more favourable. Root density is assumed to be distributed logarithmically

10 with depth. Beer`s law is used to partition the potential evapotranspiration into one fraction

11 transpirated by the canopy and the remaining fraction of evaporation from the soil. This is

12 based on the green and on the total leaf area indices, given as a function of the day number in

13 the year as user-specified input.

14 The heat conduction equation is solved using a standard Crank-Nicholson finite difference

15 scheme. The effect of soil moisture and temperature on the first-order kinetics degradation of

16 pesticides is estimated with the approach of Boesten and van der Linden (1991):

$17 \lambda=\lambda_{\text {ref }}\left(\frac{\theta}{\theta_{r e f}}\right)^{\beta} e^{\alpha\left(T-T_{r e f}\right)} \quad$ for $\quad T>5^{\circ} \mathrm{C}$

18 where $\lambda$ is the degradation rate coefficient $\left(d^{-1}\right), \lambda_{\text {ref }}$ is the reference rate coefficient $\left(d^{-1}\right), \theta_{\text {ref }}$ is

19 the reference water content $\left(\mathrm{cm} \mathrm{cm}^{-3}\right), \mathrm{T}$ is the soil temperature $\left({ }^{\circ} \mathrm{C}\right), \mathrm{T}_{\text {ref }}$ is the reference

20 temperature $\left({ }^{\circ} \mathrm{C}\right)$, and $\alpha\left({ }^{\circ} \mathrm{C}^{-1}\right)$ and $\beta(-)$ are empirical parameters. The pesticide uptake by 21 roots is modelled as a function of root water uptake and pesticide concentration. An empirical 22 concentration factor is used to define the fraction of pesticide concentration taken up by the 23 roots. 


\section{MARTHE}

2 MARTHE (Modelling Aquifers with Rectangular cells, Transport and hydrodynamics) was

3 originally developed as a 3-dimensional groundwater model designed to compute water flow

4 and solute transport in saturated porous media (Thiéry, 1995). Additional routines allow the

5 computation of unsaturated flow, thus MARTHE also solves the 3-dimensional form of the

6 Richards equation numerically. The spatial discretization is based on finite differences. The

7 resulting matrix equation is iteratively solved using conjugate gradients combined with

8 Choleski pre-conditioning. Advective, diffusive and dispersive transport can be simulated

9 using three different techniques: $\mathrm{CDE}$ based on finite differences, Total Variation

10 Diminishing and Method of Characteristics.

11 The main features of the plant module are very similar to MACRO. The evolution of the LAI

12 is a function of main development stages (i.e. germination, maturity and harvest). Like for

13 MACRO an exponential function is used to divide the potential evapotranspiration into

14 transpiration and evaporation. Canopy interception is not considered. For the root system

15 development of crops a linear growth from germination until maturity is assumed. Between

16 maturity and harvest the specified maximum root depth remains constant. The root density

17 can be calculated from several functions. During this study an exponentially decreasing root density was assumed. For the estimation of the actual transpiration the reduction according to the water stress compensation concept (Jarvis 1989) is taken into account.

The root uptake of solutes is simply calculated from a solution uptake factor (-) describing the

21 fraction of mass lost to root uptake by plants. Concerning solute degradation a sequential

22 first-order decay, a temperature and soil moisture dependent first-order decay or a simple

23 first-order decay can be taken into account. For the soil temperature and moisture dependent

24 first-order decay a parameterized Graham-Bryce approach (Graham-Bryce, 1982) or the 25 concept of Boesten and van der Linden (1991) can be used. 


\section{Model input}

3 The functional relation between pressure head, soil water content and unsaturated hydraulic

4 conductivity plays a key role for the modeling of water flow (Vereecken and Kaiser 1999;

5 Herbst et al., 2002). For MARTHE and TRACE the soil water retention function of van

6 Genuchten (1980) with parameter $m=1$ was used, which is equivalent to the equation

7 proposed by Brutsaert (1966),

$8 \quad \theta(h)=\theta_{r}+\frac{\theta_{s}-\theta_{r}}{1+(\alpha|h|)^{n}}$

9 where $\theta$ denotes the water content $\left(\mathrm{cm}^{3} \mathrm{~cm}^{-3}\right), \mathrm{h}$ is the pressure head $(\mathrm{cm}), \theta_{\mathrm{r}}$ is the residual

10 water content $\left(\mathrm{cm}^{3} \mathrm{~cm}^{-3}\right), \theta_{\mathrm{s}}$ is the water content at saturation $\left(\mathrm{cm}^{3} \mathrm{~cm}^{-3}\right), \alpha$ is the inverse of

11 the bubbling pressure $\left(\mathrm{cm}^{-1}\right)$ and the dimensionless shape parameter $\mathrm{n}(-)$.

12 By using $m=1$ instead of $m=1-1 / n$ the closed analytical expression of the Mualem/van

13 Genuchten approach (van Genuchten, 1980) for the $K(h)$ function is lost. Therefore the 14 unsaturated hydraulic conductivity function of Gardner (1958) was applied,

$15 \quad K(h)=\frac{K_{s}}{1+(b|h|)^{c}}$

16 where $\mathrm{K}$ is the unsaturated hydraulic conductivity $\left(\mathrm{cm} \mathrm{d}^{-1}\right), \mathrm{K}_{\mathrm{s}}$ is the saturated hydraulic

17 conductivity $\left(\mathrm{cm} \mathrm{d}^{-1}\right)$, and $\mathrm{b}\left(\mathrm{cm}^{-1}\right)$ and $\mathrm{c}(-)$ are empirical parameters. The soil hydraulic properties listed in Table 4 were determined by Vereecken and Kaiser (1999). They derived the soil hydraulic properties from the soil properties listed in Table 2 with the Pedotransfer functions (PTF) of Vereecken et al. (1989 and 1990) and fitted the $\theta_{\mathrm{r}}$ and $\alpha$ values. TRACE 21 and MARTHE allow for the use of the modified Mualem/van Genuchten approach described above, while MACRO is based on the common Mualem/van Genuchten approach (with m=11/n) modified for the dual porosity approach (Wilson et al., 1992; Mohanty et al., 1997; Vogel 
1 et al., 2001). In order to obtain comparable soil hydraulic functions for the Richards' equation

2 based models the retention and unsaturated hydraulic conductivity functions for MACRO

3 (Mualem/van Genuchten, $\mathrm{m}=1-1 / \mathrm{n})$ were derived in a two step procedure. First $\theta_{\mathrm{r}}, \theta_{\mathrm{s}}, \alpha, \mathrm{n}$ and

$4 \quad \mathrm{~K}_{\mathrm{s}}$ were fitted to the already available functions of Vereecken and Kaiser (1999) using the least

5 squares procedure of RETC (van Genuchten, 1991). In a second step the parameters defining the

6 macropore system the saturated matrix conductivity $\mathrm{K}_{\mathrm{mi}}\left(\mathrm{cm} \mathrm{d}^{-1}\right)$, the diffusion path length $\mathrm{a}_{\text {scale }}$

$7(\mathrm{~cm})$ and the boundary pressure head $\mathrm{C}_{\text {ten }}(\mathrm{cm})$ were calibrated on the measured MBT

8 concentrations in the drainage water (Table 4). For ANSWERS soil hydraulic parameters like

$9 \quad \mathrm{~K}_{\mathrm{s}}$ and field capacity were calculated internally with the PTF of Rawls and Brakensiek (1989)

10 from the properties given in Table 2. The use of other soil hydraulic functions is not very

11 appropriate, since the capacity based approach implemented in ANSWERS is closely linked

to the PTFs of Rawls and Brakensiek (1989). The initial values of soil moisture or pressure head for the model start were derived from the neutron probe measurements.

All the models can handle a linear, Freundlich or Langmuir sorption isotherm. For all of the models the sorption of MBT was described with a linear sorption isotherm. The values of the distribution coefficient $\mathrm{K}_{\mathrm{d}}\left(\mathrm{cm}^{3} \mathrm{~g}^{-1}\right)$ are calculated from a partition coefficient $\mathrm{K}_{\mathrm{oc}}$ of $527 \mathrm{~cm}^{3}$ $\mathrm{g}^{-1}$, found in the Agritox database (http://www.inra.fr/agritox), and the organic matter content assuming $K_{d}=K_{o c} f_{o c}$. The resulting $K_{d}$ for the three soil horizons from top to the bottom is $5.27,2.11$ and $1.58 \mathrm{~cm}^{3} \mathrm{~g}^{-1}$ respectively. Thus the retardation factor for the top horizon at water saturation is 21.2, indicating a high sorption of MBT. For MARTHE and ANSWERS a

21 temperature and soil moisture dependent degradation based on the equation of Graham-Bryce et al. (1982) is taken into account, 
1 where $\lambda$ is the degradation rate $\left(\mathrm{d}^{-1}\right), \mathrm{T}$ is the soil temperature $\left({ }^{\circ} \mathrm{K}\right), \mathrm{M}$ is the gravimetric soil

2 moisture (\%) and a (-), b (-) and $\mathrm{g}\left({ }^{\circ} \mathrm{K}\right)$ are parameters. From batch experiments Wüstemeyer

3 (2000) found the following parameters related to MBT:

$4 \quad \ln (\lambda)=7.0+1.343 \cdot \ln (M)-4476 \cdot T^{-1}$

5 From which the half-life $\left(\mathrm{DT}_{50}\right)$ can be calculated as follows:

$6 \quad D T_{50}(T, M)=\frac{\ln (2)}{\lambda(T, M)}$

7 3dLEWASTE does not account for temperature or soil moisture dependent degradation. For

8 this case a first order kinetic decay with a $\mathrm{DT}_{50}$ of $200 \mathrm{~d}$ was found after calibration. By using

9 the mean of the measured soil temperature at $10 \mathrm{~cm}$ depth $\left(\overline{T_{10}}=10.3^{\circ} \mathrm{C}\right)$ and the mean of the

10 measured soil moisture at $25 \mathrm{~cm}$ depth $\left(\overline{\theta_{25}}=0.22\right)$ a $\mathrm{DT}_{50}$ for reference conditions $\left(\mathrm{T}_{\mathrm{ref}}=20^{\circ} \mathrm{C}\right.$

11 and $\theta_{\text {ref }}=0.39$ ) of 162 days was calculated according to the approach of Boesten and van der Linden (1991). This $\mathrm{DT}_{50}$ is applied for MACRO. Figure 2 shows a comparison of the

13 Graham-Bryce approach with the Boesten and van der Linden approach. It is clearly visible,

14 that the Boesten and van der Linden approach with a reference $\mathrm{DT}_{50}$ of 162 days gives higher

15 half-lifes than the Graham-Bryce approach. Thus the remaining mass of MBT in soil should be smaller for MARTHE and ANSWERS applying the Graham-Bryce approach than for MACRO and TRACE, where the $\mathrm{DT}_{50}$ is generally higher. For all the models the degradation rate for sorbed and dissolved MBT is supposed to be the same. The dispersion length was assumed to be $1.7 \mathrm{~cm}$ for all of the models.

20 MACRO, MARTHE and ANSWERS calculate the soil temperature from daily mean air temperature by solving the equation of heat diffusion and convection. For MARTHE the mineral thermal conductivity is set to $1.5 \mathrm{~W} \mathrm{~m}^{-1}{ }^{\circ} \mathrm{C}^{-1}$, water thermal conductivity is set to 0.6

$23 \mathrm{~W} \mathrm{~m}{ }^{-1}{ }^{\circ} \mathrm{C}^{-1}$, mineral volumetric specific heat is set to $2 \cdot 10^{6} \mathrm{~J} \mathrm{~m}^{-3}{ }^{\circ} \mathrm{C}^{-1}$ and water specific heat 
1 is set to $4185 \mathrm{~J} \mathrm{~kg}^{-1}{ }^{\circ} \mathrm{C}^{-1}$. MACRO applies the approach of Jansson (1991) to estimate thermal

2 conductivity and volumetric heat capacity from the soil properties summarized in Table 2.

3 The potential reference evapotranspiration $\mathrm{ET}_{\mathrm{p}}$ (Figure 1) was calculated according to the 4 approach of Penman/Monteith (Monteith, 1975). Potential evapotranspiration and 5 precipitation are applied as the upper boundary condition, whereas a seepage face is applied to 6 the lower boundary at the bottom of the lysimeter. The seepage face boundary is characterized 7 by a no-flow boundary for unsaturated conditions:

$8 \quad q(z, t)=0 \quad$ for $\quad h<0$

9 If the seepage face becomes saturated, the boundary turns into a prescribed head boundary

10 with $\mathrm{h}(\mathrm{z}, \mathrm{t})=0$. The vertical lysimeter wall is set as a no-flow boundary condition.

11 For MACRO, MARTHE and TRACE the spatial discretization consists of 110 elements of 1

$12 \mathrm{~cm}$ thickness each. The 3-d models MARTHE and TRACE are run in a 1-d mode. Due to the 13 infiltration approach according to Green and Ampt (1911) the spatial discretization for 14 ANSWERS requires a thickness of $40 \mathrm{~cm}$ for the uppermost element. The eight elements 15 beneath have a thickness of $8.75 \mathrm{~cm}$ each.

\section{$17 \quad$ Validation criteria}

18 A commonly used criterion for model validation is the root mean square error (RMSE), where

19 the root of the mean squared residuals is calculated. The RMSE has the unit of the considered 20 variable. The squared residuals are also used for the second criterion applied, which is the 21 coefficient of model efficiency CME (Nash and Sutcliffe, 1970). Here they are used to 22 determine the proportion of the deviation from the observed mean, which can be explained by 23 the model, 
$C M E=\frac{\sum_{i=1}^{n}\left(x_{o}(t)-x_{\text {omean }}\right)^{2}{ }_{i}-\sum_{i=1}^{n}\left(x_{o}(t)-x_{s}(t)\right)^{2}{ }_{i}}{\sum_{i=1}^{n}\left(x_{o}(t)-x_{\text {omean }}\right)^{2}{ }_{i}}$

2 where $x_{0}$ is the observed value, $x_{s}$ is the simulation result at time $t$ and $x_{\text {omean }}$ is the arithmetic

3 mean of the observed values. The CME is a dimensionless criterion that can have negative

4 values. The highest value possible is 1, indicating that observation and model are completely

5 in agreement. The Index of Agreement IA (Willmott, 1981) is also dimensionless and ranges

6 between 0 and 1 :

$7 \quad \boldsymbol{I A}=1-\frac{\sum_{i=1}^{n}\left(x_{o}(t)-x_{s}(t)\right)^{2}{ }_{i}}{\sum_{i=1}^{n}\left(\left|x_{o}(t)-x_{o m e a n}\right|+\left|x_{s}(t)-x_{o m e a n}\right|\right)^{2}{ }_{i}}$

8 Because CME and IA are dimensionless, they can be used to compare the model quality

9 between different variables, while the RMSE gives an idea about the model error in the units

10 of the variable under consideration.

RESULTS

\section{Water flow}

14 One aim of this study was to identify the crucial parameters of plant related processes concerning the pesticide transport in soil. During the calibration process of the four models three crucial parameters were identified: The leaf area index LAI, the root depth $\mathrm{Rd}$ and the crop conversion factor $\mathrm{K}_{\mathrm{c}}$. Table 3 summarizes the calibrated and the original maximum values of this three parameters. Only for MACRO the maximum LAI was slightly modified during calibration. For all the crops the emergence and harvest dates were known, thus the uncertainty concerning the LAI development was rather small and modifications of the LAI

21 did not improve model results significantly. A quite large variability of the maximum LAI was detected for the different plant databases. The difference between MACRO and 
1 MARTHE, which are based on the same plant database, and ANWSERS is larger than the

2 difference between the three crops. Compared to the plant database LAIs the LAI estimated

3 with TRACE for oat is much smaller. The LAI estimated for winter wheat and winter barley

4 are much more similar. The root depth defines the zone of the soil, where the sink term of

5 transpiration influences the soil moisture. Differences between calibrated and uncalibrated

6 maximum $\mathrm{Rd}$ range between 5 and $40 \mathrm{~cm}$, for MACRO and ANSWERS respectively. The

7 crop conversion factor $\mathrm{K}_{\mathrm{c}}$ determines the amount of $\mathrm{ET}_{\mathrm{p}}$. Among this three plant parameters

8 the $\mathrm{K}_{\mathrm{c}}$ has probably the largest influence on the model results and the largest differences

9 between calibrated and uncalibrated plant parameters can be detected for the this parameter.

10 The variation of the calibrated maximum $\mathrm{K}_{\mathrm{c}}$ for different crops is large (Table 3 ). The lowest

$11 \mathrm{~K}_{\mathrm{c}}$ was found for the winter barley, while the highest values were assigned to winter wheat.

12 With ANSWERS the LAI and $\mathrm{K}_{\mathrm{c}}$ factors were unchanged during calibration. For TRACE and

13 MACRO the Rd and $\mathrm{K}_{\mathrm{c}}$-values were significantly modified during the calibration procedure.

14 The same basically holds true for MARTHE, but the $\mathrm{K}_{\mathrm{c}}$ was changed more moderately. For MARTHE a constant $\mathrm{K}_{\mathrm{c}}$ was applied for every crop, without any temporal variability

16 according to phonological stages.

The total water balance (Table 6) is well reproduced by all models. ANSWERS slightly overestimates the total amount of actual evapotranspiration $\mathrm{ET}_{\mathrm{a}}$, whereas the other models slightly underestimate the total $\mathrm{ET}_{\mathrm{a}}$. The relative errors for single water balance components are small, except for the change in soil moisture, which is merely a result of the small absolute amount of change in soil moisture.

Apart from the overall water balance, the reproduction of the temporal evolution of the water balance components is relevant. Figure 3 shows a comparison between observed and modelled cumulative actual evapotranspiration. In general the four models match the measurements, which exhibit only small standard deviations, except for the two drying 
1 periods with high evapotranspiration demands. During the first spring period (1989) all the

2 models applied slightly underestimate the amount of actual evapotranspiration. This is vice

3 versa for the second period (spring 1990), when MARTHE shows an increase in actual

4 evapotranspiration too early and too low. ANSWERS reproduces this increase too early and

5 in total too high. The calculation of the coefficient of model efficiency (CME) with the mean

6 of the measured actual evapotranspiration and the corresponding model results reveals that

7 ANSWERS, MACRO and MARTHE are close to each other in their ability to reproduce evapotranspiration while TRACE shows the highest CME (Table 5). For the models the ratio between cumulative actual evapotranspiration $\left(\mathrm{ET}_{\mathrm{a}}\right)$ and cumulative potential evapotranspiration $\left(\mathrm{ET}_{\mathrm{p}}\right)$ differs for several periods. The $\mathrm{K}_{\mathrm{c}}$-values applied already indicate this. Combined with the different reduction methods to estimate $\mathrm{ET}_{\mathrm{a}}$ from $\mathrm{ET}_{\mathrm{p}}$ for the different models the ratio between $\mathrm{ET}_{\mathrm{a}}$ and $\mathrm{ET}_{\mathrm{p}}$ shows large deviations. For example at the end of the first drying period during summer 1989 at the same day the ratio $\mathrm{ET}_{\mathrm{a}} / \mathrm{ET}_{\mathrm{p}}$ ranges between 0.65 and 1.0, for TRACE and MARTHE respectively, whereas the resulting $\mathrm{ET}_{\mathrm{a}}$ is quite similar for all models (Figure 3).

A comparison of calculated and observed volumetric soil moisture at two depths is shown in Figure 4. For the depth of $25 \mathrm{~cm}$ the first significant deviations occur during the drying period of spring 1989. During this period TRACE reproduces the drying quite accurately, whereas ANSWERS, MACRO and MARTHE exhibit a slightly delayed drying of the soil. During the following wetting period in the autumn and winter 1989 ANSWERS slightly overestimates the re-wetting while TRACE and MARTHE slightly underestimate the re-wetting. For this rewetting period MACRO is in good agreement with the measurements. Large deviations between measurements and model results in the upper layer can be observed during the second drying period of spring 1990 for ANSWERS and MARTHE. In this case ANSWERS predicts the drying too early while MARTHE underestimates the drying. MACRO 
1 underestimates the drying even more than MARTHE. Generally, for the depth of $25 \mathrm{~cm}$ all

2 the models are basically in accordance to the measurements, which is supported by the CME

3 ranging between 0.65 and 0.93 for MACRO and TRACE respectively (Table 5). For the depth

4 of $85 \mathrm{~cm}$ the results of TRACE and MARTHE are very close to each other. Both models

5 show much too high soil water contents during spring and summer 1989, although the

6 measurements show a high standard deviation during the summer 1989 when the soil was

7 very dry. In the following vegetation period (spring and summer 1990) the results of both models match the measurements. During this second period the effect of drying is much less pronounced. In contrast to this ANSWERS reproduces the decrease in soil moisture during spring and summer 1989 much better than TRACE and MARTHE. Large deviations for ANSWERS can be found for the second vegetation period where ANSWERS clearly underestimates the soil moisture. For the soil moisture of the lower layer the best performing model is MACRO with an IA of 0.96. Although the models show a quite different behaviour for the soil moisture at $85 \mathrm{~cm}$ depth the CME are quite close to each other varying between 0.70 and 0.86 . The IA is ranging even smaller, varying between 0.92 and 0.96 . In relation to the mean the standard deviation of the measured drainage is clearly higher than the standard deviation of the measured evapotranspiration. Figure 5 shows the comparison between modelled and measured cumulative drainage. During winter 1988/1989 the highest amount of drainage was measured. MACRO and TRACE underestimate this amount, while the amount estimated with ANSWERS is very close to the measurement. During the second 21 period of drainage (winter 1989/1990) compared to the measurements the results of 22 ANSWERS show a delay, but the amount of drainage is well reproduced, while TRACE clearly overestimates the amount of drainage. MARTHE shows the best agreement with the drainage measurements with the highest CME of all models. Concerning drainage MACRO shows a CME of 0.81 , although for this lysimeter experiment there is a tendency to slightly 
1 underestimate the amount of drainage water. The temporal course of drainage is well

2 reproduced.

\section{Transport of Methabenzthiazuron}

5 In the models MARTHE, MACRO and ANSWERS degradation is soil moisture and

6 temperature dependent. Figure 6 shows a comparison between the model results concerning

7 soil temperature at $10 \mathrm{~cm}$ depth. This depth was chosen because the measured soil temperature at $10 \mathrm{~cm}$ depth exhibits a high amplitude, which is a result of being close to the soil surface, where the soil heat flux is mainly driven by the atmospheric conditions.

Furthermore most of the degradation takes place in the uppermost soil layer with high organic matter content. The modelled soil temperatures of MARTHE, MACRO and ANSWERS are very close to each other and they are close to the measurements. The temporal variability of soil temperature is well reproduced by the models, which is supported by the small RMSE (Table 5). For MARTHE, MACRO and ANSWERS the degradation was calculated with the modelled soil temperature and soil moisture. Figure 7 a reveals that 252 days after application the remaining total MBT mass was found in the upper $10 \mathrm{~cm}$. This observation is generally reproduced with TRACE, MACRO and MARTHE, although the three models show a small amount of MBT in the soil layer between 10 and $20 \mathrm{~cm}$ depth. The amount of MBT in the upper $10 \mathrm{~cm}$ estimated with MARTHE is very close to the measurement while TRACE clearly overestimates the remaining mass of MBT. Related to the applied mass, TRACE estimated $12 \%$ too much. MACRO also clearly overestimates the MBT residues for the first sampling date. With ANSWERS no MBT is found in the upper compartment ( $0-40 \mathrm{~cm} \mathrm{depth})$. The total mass of MBT is found in the depth between 40 and $70 \mathrm{~cm}$. Related to the applied mass, the total mass left in the profile according to ANSWERS is $13.6 \%$ too much. 
1 After 627 days the measurements show that the total mass left in the profile is just little lower than after 252 days and it is divided into the two uppermost layers $(0-20 \mathrm{~cm})$. Compared to the measurements the results obtained with MACRO and TRACE are the closest (Figure 7b). MACRO and TRACE underestimate the amount of MBT, but they reproduce the right depth. MARTHE also reproduces the right depth, but the degradation of MBT is clearly overestimated. The same holds for ANSWERS and additionally the mass is again estimated deeper in the profile than measured.

As assumed from Figure 2 the estimated mass of MBT residuals is higher for both sampling dates for MACRO and TRACE than for MARTHE and ANSWERS. This is an effect of the higher $\mathrm{DT}_{50}$. For TRACE the $\mathrm{DT}_{50}$ is constantly 200 days, while MACRO modifies the $\mathrm{DT}_{50}$ of 162 days according to soil moisture and temperature following the approach of Boesten and van der Linden (1991). MARTHE and ANSWERS compute smaller $\mathrm{DT}_{50}$ from the Graham-Bryce equations (Eq. 10 and 11). For the first sampling date 252 days after application the RMSE calculated for the 11 depths (see Figure 7) is 30.8, 3.9, 9.7 and 11.7, for ANWERS, MARTHE, TRACE and MACRO respectively. For the second sampling 627 days after application the RMSE for the 11 depths is $13.7,10.1,5.1$ and 6.4 , respectively. The models applied with a higher $\mathrm{DT}_{50}$ (TRACE and MACRO) reproduce the measurements of the second date better than the ones of the first date. This is vice versa for MARTHE, which is based on the Graham-Bryce approach. MARTHE reproduced the measurements of the first sampling better than for the second sampling. According to Figure 8 the measured concentrations of MBT in the drainage water show a small peak roughly 100 days after application. The total mass of MBT lost by leaching during the experimental period is $14.6 \mu \mathrm{g} \mathrm{m}^{-2}$, equivalent to $0.0059 \%$ of the applied mass of MBT. None of the models predicts MBT in drainage water, except the calibrated MACRO estimates at total amount of MBT leaching of $7.8 \mu \mathrm{g} \mathrm{m}^{-2}$. MACRO was mainly calibrated on the 
1 macropore parameters listed in Table 4. Figure 8 shows that the peak of MBT leaching

2 predicted with MACRO is a little delayed, and the total amount of MBT leaching is

3 underestimated. Apart from the calibration of the macropore parameters with the water

4 balance components the fraction of sorption sites in the macropores was calibrated with the

5 measured MBT leaching, $\mathrm{f}_{\mathrm{mac}}$ was set to $0.005(-)$, which corresponds to the small macropore

6 volume fraction $\left(\theta_{\mathrm{s}}-\theta_{\mathrm{b}}\right.$, Table 4$)$.

7

8

9

\section{DISCUSSION}

Three crucial parameters were identified during the calibration procedure. The calibration of the LAI was moderate, probably due to the exactly known emergence and harvest dates. A striking point is the higher variability between different plant databases than between calibrated and uncalibrated model parameters. A query at the plant parameter database (PlaPaDa, Breuer and Frede, 2003) revealed LAIs between 2.3 and 4.6 for winter wheat. This shows the variability of this parameter for different environmental conditions, and it might indicate that the model functions are adapted to the related plant database. Like the LAI the root depths were rather moderately calibrated, except for the root depth of oat. For this crop three of the four modellers increased the root depth. From the calibration of LAI and root depth it could be assumed that the chosen databases of Knisel (1993), Van Heemst (1988) and FOCUS (2000) in combination with the chosen model are generally applicable to the Zwischenscholle test site. The really important plant parameter is the crop conversion factor $\mathrm{K}_{\mathrm{c}}$. This parameter has a strong influence on the overall water balance. Except for ANSWERS all models were calibrated on $\mathrm{K}_{\mathrm{c}}$ for each of the crops. For winter wheat and oat the $\mathrm{K}_{\mathrm{c}}$ values were increased, while for winter barley $\mathrm{K}_{\mathrm{c}}$ was decreased. The decrease of the $\mathrm{K}_{\mathrm{c}}$ for winter barley was required to account for the effect of a plant disease keeping the barley from a normal plant development. Against this background and having in mind the amount of 
1 calibration of $\mathrm{K}_{\mathrm{c}}$ even for this parameter the selected databases are basically applicable for the

2 Zwischenscholle. But care should be taken not to underestimate the actual evapotranspiration

3 by using $\mathrm{K}_{\mathrm{c}}$ values that are too small. This can only be checked in terms of the water balance.

4 Further there might be, compared to the field situation, generally a slightly higher 5 evapotranspiration for lysimeters. Bergström and Jarvis (1994) and Boesten (1994) attribute

6 this to the 'oasis effect', i.e. the lysimeters are partially surrounded by hard surfaces without

7 any evaporation, which presumably causes in combination with wind a lateral flow of dry air over the lysimeters, thereby increasing the evapotranspiration of the lysimeters.

As expected the soil moisture near the soil surface is clearly influenced by evapotranspiration.

This is reflected in the model results. If the model correctly reproduces the amount of transpiration and evaporation the soil moisture at the depth of $25 \mathrm{~cm}$ is well described. Supported by the CME and IA all the model results for evapotranspiration and soil moisture at $25 \mathrm{~cm}$ depth are clearly acceptable, which is basically the result of well described plant related processes from the calibration of plant parameters. The soil moisture at the depth of $85 \mathrm{~cm}$ is influenced by root water uptake and drainage. Even for the soil moisture at $85 \mathrm{~cm}$ a proper reproduction can be stated for all the models (Table 5), whereas the temporal course of drainage is reproduced with different quality. According to Nash and Sutcliffe (1970) a model with CME lower than 0.5 should be rejected. With a CME of 0.1 ANSWERS is below this threshold and even TRACE is quite close to this value having a CME of 0.58. The use of a criterion like the CME is supposed to support the validation of models by bringing in an objective component, but it is still the model user to decide whether a model should be rejected or not. The IA for the drainage estimated with ANSWERS and TRACE, 0.67 and 0.89 respectively, is in an acceptable range. The total amount of drainage estimated by ANSWERS and TRACE is close to the measurements. And Figure 5 also reveals, that the variation of drainage with time is generally reproduced. Thus the modelling of drainage with 
1 ANSWERS and TRACE is still acceptable, although this variable is not as well reproduced as

2 the other water flow variables. It would be expected that the drainage flow could be well

3 described, if also the soil moisture close to the lower boundary of the lysimeter is well

4 described. This is true for MARTHE and MACRO, but not for ANSWERS and TRACE.

5 According to the validation criteria TRACE reproduces the soil moisture at $85 \mathrm{~cm}$ even

6 slightly better than MARTHE. But the drainage is described significantly better by

7 MARTHE. The validation criteria for the soil moisture at $85 \mathrm{~cm}$ calculated with ANSWERS

8 are in the same range for all the models, while the drainage is not that well reproduced. For

9 ANSWERS this effect might be attributed to the capacity based approach for water flow,

10 because the estimation of the drainage is not completely consistent with the lower boundary

11 condition of the lysimeter experiment.

12 In contrast to the water flow the modelling of the fate of MBT is rather problematic.

MARTHE, ANSWERS and MACRO account for a soil temperature and moisture dependency

of degradation. The model variables soil temperature and soil moisture near the surface are

well described (Table 5), whereas the degradation of MBT is not that well described. It seems

like the modelling of soil moisture and temperature is easier than the quantification of the relation between degradation and soil moisture/temperature. Basically the models can be divided into two groups. One group is TRACE and MACRO using a long half-life and predicting the long-term behaviour correctly. The other group is MARTHE and ANSWERS using a clearly shorter half-life and predicting the amount of MBT residues of the first sampling date (252 days after application) correctly but for the last sampling (627 days after application) the residues are underestimated. Probably the first order kinetics approach applied for all models is not suitable to describe the degradation of MBT (Diekkrüger et al. 1995b). The first order kinetics approach might by appropriate to describe the short-term behaviour of the MBT degradation, but the long-term behaviour might be influenced by a 
1 very slow sorption/desorption kinetic. Then a hockey stick degradation function might be

2 more appropriate. A validation of this statement from the data used in this study is limited,

3 because a longer monitoring with more sampling dates would be required. This would also be

4 necessary to decide if the moisture and temperature dependent first order decay is superior to

5 the simple first order decay. The degradation rates of MBT in literature vary between 30 days

6 (Rouchaud et al., 1988), 139 days (Jarvis, 1995) and 172 days (Wüstemeyer, 2000) under

7 field conditions. This might be another hint to a slow sorption/desorption kinetic for the long-

8 term behaviour of MBT.

9 A leaching of $0.0059 \%$ of the applied mass of MBT occurs. This process can be described with MACRO only after calibration. Without the calibration of the macropore soil hydraulic properties and the fraction of sorption sites in the macropores no leaching was estimated with MACRO. This contributes to the findings of Bergström and Jarvis (1994), where only after calibration the pesticide leaching due to preferential flow is well described. For registration purposes in Europe a leaching level of $0.1 \%$ or more of the applied dose is relevant (Vanclooster et al., 2000). From this point of view the small amount of MBT leaching is not relevant, nevertheless there is a small lack of transport process description detected for TRACE, ANSWERS and MARTHE.

For the reproduction of evapotranspiration, soil moisture and drainage basically all model concepts are suitable. For the description of degradation the performance of the simple first order kinetics is comparable to the temperature and soil moisture dependent first order concepts. Here a more extensive data set on MBT residues will probably reveal the better performance of the more sophisticated approach taking soil moisture and temperature into account. Further improvement of the description of degradation might be possible with a nested first order approach allowing for different half-lifes for the short-term and the longterm behaviour of pesticide degradation. The biggest conceptual constraint concerning 
1 pesticide fate was detected for ANSWERS. Due to the thickness of the uppermost element,

2 necessary for the Green and Ampt infiltration, the transport of the pesticide cannot be

3 described if the downward movement of the compound is very small. The center of mass

4 predicted with ANSWERS is always much too deep in the profile. And degradation and

5 sorption occur usually very close to the surface, which cannot be described properly with

6 ANSWERS. The other conceptual constraint can be detected for MARTHE, TRACE and

7 ANSWERS. These models are unable to describe preferential flow, which must be seen

8 against the background of the difficult parameter identification. The problem of the derivation

9 of macropore parameters will increase with scale and a process can only be taken into account

10 if also the parameters are available.

11 The use of five parallel lysimeters revealed a high variability of measured drainage amounts,

12 while the evapotranspiration is rather similar. The cores were sampled quite close to each

13 other $(\sim 1 \mathrm{~m})$, indicating that the spatial variability of soil properties is high. Even the use of

14 five parallel lysimeters involves still a large uncertainty concerning the field scale drainage

15 amount. Thus the lysimeter concept is probably not able to capture the field scale

16 heterogeneity of processes strongly influenced by the spatial variability of soil properties.

17

18

19

\section{CONCLUSIONS}

During the calibration of plant parameters three crucial parameters were identified: the LAI, the root depth and the crop conversion factor. Among these parameters the crop conversion factor values were changed significantly during calibration. For most cases the $\mathrm{K}_{\mathrm{c}}$ was increased which is seen as a result of the lysimeter set up for the measurement of the actual evapotranspiration. Generally the selected databases of plant parameters are applicable to the 'Zwischenscholle' test area. 
1 Having in mind that only the plant parameter values were calibrated, the water flow is well

2 described with all the model concepts, which is proved by the calculated validation criteria.

3 The fate of MBT is not as well described as the water flow. The residues of MBT are

4 estimated for the right depth with MACRO, MARTHE and TRACE. But the amounts of MBT

5 residues are only poorly reproduced. Laboratory measured soil moisture and temperature

6 dependent half-life does not improve the modeling of degradation significantly. More

7 extensive data on MBT residues would be needed to verify a slow sorption/desorption kinetic,

8 which also calls the first order approach applied for all model used in this study into question.

9 A very small amount of MBT leaching can be described with MACRO, but only after 10 extensive calibration.

11 Basically all the model concepts are well applicable for water flow. The amount of 12 preferential flow not considered with TRACE, ANWERS and MARTHE is not significant for 13 the water flow but for the MBT leaching. A conceptual limitation was found for the capacity 14 based ANSWERS. Here the Green and Ampt equation for infiltration requires a very thick 15 uppermost element hindering the sound estimation of transport and degradation of MBT close 16 to the surface.

17

\section{ACKNOWLEDGEMENT}

19 The authors acknowledge financial support by the EU within the framework of PEGASE, 20 contract EVK1-CT1999-00028. 


\section{REFERENCES}

Armstrong, A., K. Aden, N. Amraoui, B. Diekkrüger, N. Jarvis, C. Mouvet, P. Nicolls and C. Wittwer. 2000. Comparison of pesticide leaching models: results using the Brimstone Farm data set. Agricultural Water Management 44:153-181.

Bergström, L. 1990. Use of lysmeters to estimate leaching of pesticides in agricultural soils. Environmental Pollution 67:325-347.

Bergström, L.F. and N.J. Jarvis. 1994. Evaluation and comparison of pesticide leaching models for registration purposes. J. Environm. Sci. Health 29:1061-1072.

Boesten, J.J.T.I. and A.M.A van der Linden. 1991. Modelling the influence of sorption and transformation on pesticide leaching and persistence. Journal of Environmental Quality 29: 917-925.

Boesten, J.J.T.I. 1994. Simulation of bentazon leaching in sandy soil from Mellby (Sweden) with the PESTLA model. Journal of Environmental Science and Health, Part A 29:12311253

Bouraoui, F., G. Vachaud, R. Haverkamp and B. Normand. 1997. A distributed physical approach for surface-subsurface water transport modeling in agricultural watersheds. J. of Hydrology 203:79-92.

Breuer, L. and H. Frede. 2003. PlaPaDa - an online plant parameter data drill for eco-hydrological modelling approaches. (http://www.uni-giessen.de/ gh1461/plapada/ plapada.html).

Brooks, R.H. and Corey, A.T. 1964. Hydraulic Properties of Porous Media. Hydrology Paper No. 3. Colorado State Univ., Fort Collins. Colorado.

Brutsaert, W. 1966. Probability laws for poresize distributions. Soil Science 101:85-92. 
1 Celia, M.A., E.T. Bouloutas and R.L. Zarba. 1990. A general mass-conservative numerical

2 solution for the unsaturated flow equation, Water Resour. Res. 26(7): 1483-1496.

3 Diekkrüger, B., D. Söndgerath, K.C. Kersebaum and C.W. McVoy. 1995a. Validity of data set. Ecological modelling 81:3-29.

Diekkrüger, B. , P. Nörteshäuser and O. Richter. 1995b. Modeling pesticide dynamics of a loam site using HERBSIM and SIMULAT. Ecological Modelling 81:111-119.

Doorenbos, J and W.O. Pruitt. 1977. Crop Water Requirements. FAO. Irrigation and Drainage Paper 24. Rome, Italy.

Feddes, R.A., P.J. Kowalijk and H. Zaradny. 1978. Simulation of field water use and crop yield. Simulation Monographs, PUDOC. Wageningen. The Netherlands. 189 pp.

FOCUS, 2000. 'FOCUS groundwater scenarios in the EU review of active substances'. Report of the FOCUS groundwater scenario workgroup. EC Document Reference

Francaviglia, R., E. Capri, M. Klein, J. Hosang, K. Aden, M. Trevisan and G. Errera. 2000. Comparing and evaluating pesticide leaching models: results for the Tor Mancina data set (Italy), Agricultural Water Management 44:135-151.

Gardner, W.R. 1958. Some steady state solutions of the unsaturated moisture flow equation with application to evaporation from a water table. Soil Science 85:228-232.

Germann, P. 1985. Kinematic wave approach to infiltration and drainage into and from soil macropores. Transactions of the ASAE 28:745-749.

Gottesbüren, B., K. Aden, I. Bärlund, C. Brown, M. Dust, G. Görlitz, N. Jarvis, S. Rekolainen and H. Schäfer. 2000. Comparison of pesticide leaching models: results using the Weiherbach data set. Agricultural Water Management 44:153-181. 
1 Graham-Bryce, I.J., P.H Nicholls, R.J. Baker, R.J. Hance, S.J. Embling and D. Hill, 1982.

2 Movement of fluometuron and ${ }^{36} \mathrm{Cl}^{-}$in soil under field conditions: Computer simulations. $3 \quad$ Weed Res. 22:271-283.

4 Green, W.H. and G.A. Ampt. 1911. Studies in soil physics. I. The flow of air and water through soils. J. Agr. Sci. 4:1-24.

Herbst, M. and B. Diekkrüger. 2002. The influence of the spatial structure of soil properties on water balance modeling in a microscale catchment, Physics and Chemistry of the Earth 27:701-710

Jansson, P.E. 1991. Simulation model for soil water and heat conditions. Description of the SOIL model. Report 165, Div. of Agric. Hydrotechn., Dept. Soil Sci., Swedish Univ. Agric. Sci.72 pp. Uppsala

Jarvis, N.J. 1989. A simple empirical model of root water uptake. Journal of Hydrology 105:57-72.

Jarvis, N.J., 1995. Simulation of soil water dynamics and herbicide persistence in a silt loam soil using the MACRO model. Ecological Modelling 81:97-109.

Jarvis, N.J. ,XXXX. 2004 .Macro5.0 XXXXXXX, submitted to Vadose Zone Journal

Jene, B., G. Fent and R. Kubiak. 1997. Comparison of lysimeters to the actual field situation with regard to the movement of soil water and a ${ }^{14} \mathrm{C}$-labelled herbicide and bromide. The environmental fate of Xenobiotics (eds. Del Re, A.A.M., E. Capri, P. Evans and M. Trevisan). 179-186.

Keller, K.E. and J.B. Weber. 1995. Mobility and Dissipitation of 14C-labeled atrazine, Metolachlor, and Primisulfuron in undisturbed field lysimeters of a coastal plain soil. J. Agric. Food Chem. 43:1067-1086

Knisel, W.G. (Ed.). 1993. GLEAMS Groundwater loading effects of agricultural management systems, Version 2.10. Dept. Publication No. 5. Biological \& Agricultural Engineering 
Department, University of Georgia Coastal Plain Experimental Station. Tifton. 260 pp. http:/www.cpes.peachnet.edu/sewrl/Gleams/gleams_y2k_update.htm

Kosky, K.M. and B.A. Engel. 1997. Evaluation of three distributed parameter hydrologic/water quality models. ASAE Paper No. 97-2010. In the mini-conference on applications of emerging technologies in hydrology. (eds. Ward, A.D. and B.N. Wilson). ASAE. St. Joseph. MI.

Mikata, K., F. Schnöder, C. Braunwarth, K. Ohta and S. Tashiro. 2003. Mobility and degradation of the herbicide imazosulfuron in lysimeters under field conditions. J. Agric. Food Chem. 51:177-182.

Mohanty, B., R.S. Bowman, J.M.H. Hendrickx and M.T. van Genuchten. 1997. New piecewise-continuous hydraulic functions for modelling preferential flow in an intermittent flood-irrigated field. Water Resources Research 33: 2049-2063

Monteith, J. L. 1975. Vegetation and the atmosphere. 439 pp. Academic Press.

Nash, J.E and J.V. Sutcliffe. 1970. River flow forecasting through conceptual models: Part I A discussion of principles. Journal of Hydrology 10:282-290.

Rawls, W.J. and D.L. Brakensiek. 1989. Estimation of soil retention and hydraulic properties. In: Unsaturated Flow in Hydrologic Modeling: Theory and Practice, H.J. Morel-Seytoux (Eds.).NATO ASI series c 275: 275-300. Kluwer Acad. Press.

Rouchaud, J, P. Roucourt, M. Van Himme, F. Benoit, N. Ceustermans, J. Gillet, W. Plumier and G. Vulsteke. 1988. Metabolism of methabenzthiazuron in the soil of pea crops. J. Agric. Food. Chem. 36:642-645

Pennel, K.D., A.G. Hornby, R.E. Jessup and P.S.C. Rao.1993. Evaluation of five simulation models for predicting aldicarb and bromide under field conditions. Water Resources Res. 26(11):2679-2693.

Ritchie, J.T. 1972. Model for predicting evaporation from a row crop with incomplete cover. 
Schoen, R., J.P. Gaudet and T. Bariac. 1999. Preferential flow and solute transport in a large lysimeter, under controlled boundary conditions. Journal of Hydrology 215:70-81.

Spitters, C.J.T., H. van Keulen and H. van Kraalingen. 1988. A simple but universal crop growth simulation model, SUCROS87. In R. Rabbinge, H. Van Laar \& Ward (ed), Simulation and system management in crop protection. Simulation Monographs. PUDOC, Wageningen.

Thiéry, D. 1995. Modélisation 3D du transport de masse avec le logiciel MARTHE, version 5.4. BRGM report, R 38149 HYT/DR 95, 171 pp. Orleans.

Tiktak, A. 2000. Application of pesticide simulation models to the Vredepeel dataset II Pesticide fate. Agricultural Water Management 44:119-134.

Vanclooster, M. and J.J.T.I. Boesten. 2000. Application of pesticide simulation models to the Vredepeel dataset I. Water, solute and heat transport. Agricultural Water Management 44:105-117.

Vanclooster, M., J.J.T.I. Boesten, M. Trevisan, C.D. Brown, E. Capri, O.M. Eklo, B. Gottesbüren, V. Gouy and A.M.A. van der Linden. 2000. A European test of pesticideleaching models: methodology and major recommendations. Agricultural Water Management 44:1-19.

Van Genuchten, M.Th. 1980. A closed form equation for predicting the hydraulic conductivity of unsaturated soils. Soil Sci. Soc. of Am. J. 44: 892-898.

Van Genuchten, M.Th., F.J. Leij and S.R. Yates. 1991. The RETC Code for Quantifying the Hydraulic Functions of Unsaturated Soils. U.S. Salinity Laboratory EPA/600/2-91/065. 85 pp. Riverside. California. 
1 Van Heemst, H.D.J. 1988. Plant data values required for simple crop growth simulation

2 models: review and bibliography, Simulation Report CABO-TT nr. 17. Wageningen.

3 Vereecken, H., J. Feyen, J. Maes and P. Darius.1989. Estimating the soil moisture retention

4 characteristic from texture, bulk density and carbon content, Soil Science 148:389-403.

Vereecken, H., J. Maes and J. Feyen. 1990: Estimating unsaturated hydraulic conductivity from easily measured soil properties, Soil Science, 149:1-12.

Vereecken, H., G. Lindenmayr, O. Neuendorf, U. Döring and R. Seidemann. 1994. TRACE A mathematical model for reactive transport in 3D variably saturated porous media, Internal Report KFA-ICG-4-501494, Jülich.

Vereecken, H. and R. Kaiser. 1999. Analysis of multi-step outflow data and pedotransfer functions to characterise soil water and solute transport at different scales. In M. Th. van Genuchten, F.J. Leij and L. Wu (ed.) Characterization and measurement of the hydraulic

Vink, J.P.M., B. Gottesbüren, B. Diekkrüger and S.E.A.T.M. van der Zee. 1997. Simulation and model comparison of unsaturated movement of pesticides from a large clay lysimeter.

Vogel, T., M.T. van Genuchten and M. Cislerova. 2001. Effect of the shape of the soil hydrulic functions near saturation on variably-saturazed flow predictions. Advances in

Willmott, C.J. 1981. On the validation of models. Physical Geography 2.

Wilson, G.V., P.M. Jardine, and J.P. Gwo. 1992. Modeling the hydraulic properties of a multiregion soil. Soil Science Society of America Journal 56:1731-1737.

Wüstemeyer, A. 2000. Abbau und Transport von Ethidimuron und Methabenzthiazuron in einer Parabraunerde-Beitrag zur Validierung des Lysimeterkonzepts. PhD Thesis. Jülich, 
2 Yeh, G.T., P. Sharp-Hansen, B. Lester, R. Strobl and J. Scarbrough. 1992. 3 3DFEMWATER/3DLEWASTE: Numerical codes for delineating wellhead protection 4 areas in agricultural regions based on the assimilative capacity criterion, U.S. $5 \quad$ Environmental Protection Agency, GA 30613, Athens. 


\section{FIGURE CAPTIONS}

2

3 Fig. 1. Measured atmospheric conditions and calculated reference evapotranspiration during

4 the experimental period.

5 Fig. 2. Isoline plot of soil temperature and moisture dependent $\mathrm{DT}_{50}$ for MBT calculated

6 according to Graham-Bryce (Wüstemeyer, 2000) and according to Boesten and van der

7 Linden (1991), with reference $\mathrm{DT}_{50}=162 \mathrm{~d}, \theta_{\mathrm{ref}}=0.39 \mathrm{~cm}^{3} \mathrm{~cm}^{-3}, \alpha=0.01 \mathrm{~K}^{-1}, \beta=0.2$ and

$8 \mathrm{~T}_{\text {ref }}=20^{\circ} \mathrm{C}$ (Eq. 6). Volumetric water content was transformed to gravimetric with the topsoil

9 bulk density of $1.57 \mathrm{~g} \mathrm{~cm}^{-2}$.

10 Fig. 3. Measured and predicted actual evapotranspiration (cumulative). Bars are standard

11 deviations of measurements.

12 Fig. 4. Measured and predicted soil moisture at two depths. Bars are standard deviations of 13 measurements.

14 Fig. 5. Measured and predicted drainage (cumulative). Bars are standard deviations of 15 measurements.

16 Fig. 6. Measured and predicted soil temperature at $10 \mathrm{~cm}$ depth.

17 Fig. 7. Measured and predicted MBT residues (applied MBT $=100 \%) 252$ days (a) and 627

18 days (b) after application.

19 Fig. 8. Accumulated mass of measured MBT in drainage water and model results 